Article

\title{
Communicating Sustainability to Ethnocentric Consumers in China: Focusing on Social Distance from Foreign Corporations
}

\author{
Gain Park ${ }^{1}$ (D) and Hyun Soon Park ${ }^{2, *(D)}$ \\ 1 Department of Journalism and Media Studies, New Mexico State University, Las Cruces, NM 88003, USA; \\ park@nmsu.edu \\ 2 Department of Media and Communication, Sungkyunkwan University, Seoul 03063, Korea \\ * Correspondence: serenity@skku.edu
}

\section{check for}

updates

Citation: Park, G.; Park, H.S. Communicating Sustainability to Ethnocentric Consumers in China: Focusing on Social Distance from Foreign Corporations. Sustainability 2021, 13, 47. http:/ /dx.doi.org/10.3390/su13010047

Received: 31 October 2020

Accepted: 19 December 2020

Published: 23 December 2020

Publisher's Note: MDPI stays neutral with regard to jurisdictional claims in published maps and institutional affiliations.

Copyright: () 2020 by the authors. Licensee MDPI, Basel, Switzerland. This article is an open access article distributed under the terms and conditions of the Creative Commons Attribution (CC BY) license (https: / / creativecommons.org / licenses/by/4.0/).

\begin{abstract}
This study examines the relationship between social distance perception and company/sustainability campaign evaluations. The study also investigates the moderating role of consumer ethnocentrism in the relationship between the variables. This study further compares the effects of construal message framing (high-level vs. low-level construal) on social distance perception. The SPSS PROCESS macro analysis revealed that social distance perception from a corporation negatively affects company evaluations. Moreover, the results demonstrated that consumer ethnocentrism significantly moderates the relationship between social distance perception and company/sustainability campaign evaluations. Finally, the results indicate that construal message framing significantly affects the level of social distance perception from the host of a sustainability campaign. This paper provides practical suggestions for corporates' sustainability communications and adds to the literature on the reverse effect of construal level theory and social distance reduction.
\end{abstract}

Keywords: sustainability communication; construal level theory; consumer ethnocentrism; social distance; consumer evaluation

\section{Introduction}

China is an attractive market for global enterprises due to the cost of human resources and large domestic market size as well as its economic power. However, unlike the advantages of its business environment, the negative consumer sentiment from foreign brands has presented challenges and notable disadvantages to foreign enterprises in China. The anger and rejection that Chinese consumers showed in the Carrefour boycott in 2008, anti-Japanese demonstrations in 2012 [1], and the consumer backlash against Dolce and Gabbana in 2018 [2] demonstrate the existence of the anti-foreign sentiment.

It is difficult for foreign firms to compete in the market with only tangible competitiveness, but first, they must gain social legitimacy and corporate citizenship to be socially accepted in the market. The sustainability initiative is one of the key factors influencing foreign firms to overcome the social liability of foreignness (LOF). Chinese consumers and the government push foreign firms to take more sustainability responsibilities with higher consumer expectations and stricter sustainability regulations for foreign firms [2,3]. Such tendencies accelerated after the Beijing Olympics, which promoted civic participation in China; the "new normal" theme proposed by President Xi Jinping to focus on sustainable development has added even more pressure to foreign firms in China to comply with higher expectations of the government as well as of the people [3]. Studies support this view by indicating that foreign firms tend to put more effort into corporate social responsibility (CSR) [4] and spend more on CSR, compared to domestic firms in emerging markets [5].

However, the problem is that conducting sustainability campaigns does not promise positive consumer evaluations, because psychological distance between consumers and foreign firms hinders the effectiveness of sustainability campaign in gaining positive consumer evaluations. A considerable amount of research has supported the negative effect of 
this psychological social distance on positivity [6], attraction [7], credibility [8,9], willingness to support [10], interpersonal ties and solidarity [11], trust, reciprocity, altruism [12], consumer evaluations of CSR initiatives [13], and moral judgments [14]. These studies indicate that it is the perception of social distance between "you" and "me" that affects the evaluations about "you" and "what you do". This implies that the greater the social distance perception, the greater the disadvantages companies will face in a foreign market. This is a demotivating and costly concern for foreign firms as sustainability regulations are becoming stricter [3,15], which will lead to increased compliance costs with a lack of consumer recognition.

To address this issue, there have been attempts to clarify the disadvantages of foreign firms in host countries [16-19]. However, we started this study as the majority of the discussion has been centered on analyzing the discrimination and the costs from corporations perspectives, ignoring the role of consumer psychology and evaluations [19]. Moreover, there is not sufficient research suggesting practical solutions to reduce the perceived social distance, to help gain positive consumer evaluations, and to overcome the discrimination for being foreign in host countries. We argue that there should be more studies to address the problem of LOF from a communications approach and to focus on the social aspects of LOF. To that end, this study attempts to propose a communication strategy to reduce social distance and enhance consumer evaluations of foreign companies and their sustainability campaigns. We argue that this is an important strategic point in overcoming discrimination for foreign firms, not only because of the significant influence of social distance on foreign firms' survivability but also because social distance is among the few controllable barriers of foreign firms, compared to other elements of foreignness such as institutional, political, economic, and geographic distance.

The effect of construal level theory (CLT) provides a practical guide to designing strategic communication for such an objective. CLT posits that social distance is correlated with construal levels, and by framing messages with different construal levels (high-level construal vs. low-level construal), the size of the perceived social distance can be controlled; a high-level construal generates greater social distance perception, whereas a low-level construal generates less social distance perception.

To fulfill the purpose of this study, we tested the influence of social distance on consumer evaluations of a sustainability campaign and the host company. We also examined the moderating role of consumer ethnocentrism to further explain the relationship between social distance and consumer evaluations. Finally, this study tested the effect of construal level framing on social distance by comparing two different message types (high-level construal vs. low-level construal), in other words, by highlighting either the ends of an action or the means. In sum, this paper provides an understanding of (1) how social distance affects consumer evaluations, (2) how the level of consumer ethnocentrism affects the relationship, and (3) how the construal level framing influences the perceived social distance.

The following chapters will discuss the relationship between social distance, sustainability campaign initiatives, and company evaluations, the role of consumer ethnocentrism in the relationship, and the effect of construal levels on social distance perception. The sampling, study design, and operationalization will be discussed followed by the results of moderated mediation analysis and ANOVA. The practical suggestions for sustainability campaign practitioners and theoretical contributions to the CLT literature will be discussed.

\section{Theoretical Background}

\subsection{The Mediating Role of Sustainability Campaign Initiatives between Social Distance and Company Evaluations}

The association between CSR campaign evaluations and consumer evaluations such as corporate image and purchase intentions has been found in a considerable number of studies [13,20-24]. Through sustainability activities, foreign firms can persuade local consumers that they are beneficial to society and help align their values and beliefs with local consumers. Sharing common values and beliefs with companies leads consumers to 
identify them with the companies [25] and reduces social distance [26], thus enhancing consumer loyalty, support, relationship quality, and general company evaluations $[25,27]$. This approach is especially effective because people have the desire to categorize themselves into groups according to their cognitions and values and to draw a line between the ingroup and out-group [28].

However, in reality, foreign corporations often suffer from high costs [16], low consumer evaluations [17], and low credibility [13] when carrying out socially desirable activities in host countries. Moreover, Maruyama and $\mathrm{Wu}$ [18] argue that there is no effect of corporate social responsibility (CSR) in reducing the discrimination hazards of foreign firms. These findings indicate that doing good does not guarantee positive evaluations. It is also noted that CSR campaigns may even cause the backfire effect for the companies with negative reputations [20], which may also apply to foreign firms that suffer from no or negative company images.

Social distance perception or the perception of dissimilarity between consumers and foreign companies has been accused of weakening the positive effect of socially desirable activities. For example, Lii, Wu, and Ding [13] compared the effects of a CSR initiative between a company with high social distance and low social distance. The results indicate that people undervalue a CSR campaign and show a lower increase in brand evaluations when the campaign is conducted by a socially distant brand, compared to a socially close brand [13]. Such an unfair consumer evaluation has been a major discouragement for companies doing global CSR initiatives [16] and has pushed foreign firms to settle for passive and mandatory CSR activities, which is a loss for both foreign firms and society.

To discuss and solve such problems, a considerable number of studies have addressed LOF in foreign firms' sustainability initiatives [13,16-18]. However, to the best of our knowledge, the majority of the discussion has been centered on revealing whether such discrimination exists. We argue that consumer evaluations should be at the center of sustainability campaign strategies, and the psychological LOF should be considered as important as the physical costs of foreign firms [29].

To that end, this study was first proposed to examine the effect of consumers' perceived social distance from a company on both sustainability campaign evaluations and corporate evaluations. Moreover, we further tested the positive effect of campaign evaluations on company evaluations as well as the meditating role of campaign evaluations in the relationship between social distance perception and company evaluations.

Hypothesis 1 (H1). Social distance perception from a company will negatively affect sustainability campaign evaluations.

Hypothesis 2 (H2). Social distance perception from a company will negatively affect company evaluations.

Hypothesis 3 (H3). Sustainability campaign evaluations will positively affect company evaluations.

Hypothesis 4 (H4). Sustainability campaign evaluations will mediate the effect of social distance perception on company evaluations.

\subsection{The Moderating Role of Consumer Ethnocentrism}

Ethnocentrism is a term that describes when people are bound up in their immediate surroundings and believe that they are the "center of the universe" [29] (p. 280). Ethnocentric consumers choose domestic products even though the perception of the product quality is lower than foreign products because they believe that foreign companies cause an economic downturn and job losses [30,31].

Moreover, studies of consumer ethnocentrism have highlighted the moderating role of consumer ethnocentrism in consumer evaluations. For example, Supphellen and Grøn- 
haug [32] found that consumer ethnocentrism moderates the effect of foreign brand personalities. To be more specific, they found that only the low consumer ethnocentric group is affected by foreign brand personalities beyond its nationality. This implies that non-ethnocentric consumers evaluate foreign firms by what they do or how they do it, whereas ethnocentric consumers make biased evaluations depending on a company's nationality [30]. Based on Shimp and Sharma's [29] (p. 280) argument that ethnocentric consumers reject objects that are dissimilar to themselves or farther away from their "center", we assume that the effect of social distance on consumer evaluations will be moderated by consumer ethnocentrism.

As shown in the recent issues relating to consumer ethnocentrism in China, China is a market with relatively higher consumer ethnocentrism [30]. However, we assume that in a large and rapidly changing country such as China, there should be varying levels of consumer ethnocentrism within the country. Therefore, this study measures the level of consumer ethnocentrism to examine how it moderates the relationship between social distance and company/sustainability campaign evaluations and to proposes that the negative effect of social distance will be only valid or more prominent among highly ethnocentric consumers.

\subsection{Social Distance and Construal Level Theory}

Another key question of this study is whether social distance perception is controllable. Construal level theory (CLT) provides a useful framework for this question. According to CLT, people are egocentric and can only directly experience the present, here, and the self [33]. People can still process information that is psychologically distant from themselves, but they use different mental representations for the distant versus near objects. For example, imagine your close friend buying a house and also imagine a stranger buying a house. How differently would you mentally represent the same event depending on the actor? CLT posits that people use a high-level construal to represent a psychologically distant object or event, whereas people use low-level construal when there is near psychological distance [34]. A high-level construal indicates abstract mental representation, which is related to goals or desirability of an event (e.g., moving to a bigger house with beautiful scenery), whereas a low-level construal indicates concrete mental representation, which is related to the means or feasibility of an event (e.g., hiring a moving company) [33,34]. In the context of consumer evaluations, a sustainability campaign conducted by a socially distant foreign company would activate a high-level construal, desirability, or the end state such as environmental benefits or the reasons "why" the campaign is desirable. On contrary, a local company's campaign would activate a low-level construal, feasibility, or the means to an end state such as the details of "how" to conduct the campaign $[33,34]$.

To support such propositions, a considerable amount of research has studied the correlation between psychological distance and information processing, decision making, and evaluations. For example, Fujita, Henderson, Eng, Trope, and Liberman [35] found that people rely more on ends when identifying spatially distant actions, while people rely more on means when identifying spatially near actions. Moreover, Liberman and Trope [36] found that real-life choices relating to either temporally near and distant events are construed on a low-level construal (feasibility) and a high-level construal (desirability), respectively. To be more specific, when carrying out a near-future assignment, people tend to give more weight to the ease of the task (feasibility), whereas for a distant future project, people sacrifice the ease of the task for interest (desirability). Liviatan, Trope, and Liberman [34] found similar effects on the information process and judgment in the context of social distance perception. To be more specific, participants were exposed to a short story about either a socially close or distant target and asked to restate their actions; the result showed that people tend to describe a socially distant target's actions (e.g., locking a door) by emphasizing desirability (e.g., securing the house) and a socially close target's actions by emphasizing feasibility (e.g., putting a key in the lock) [34]. 
We reasoned that if social distance leads to a high-level construal, activating different levels of construal may reversely affect the level of the perceived social distance from an object. Based on such an assumption, our question extends to ask whether we can reduce consumers' social distance perception from foreign firms by manipulating construal levels in a sustainability campaign message. Liberman and Förster [37] tested this reverse effect of construal levels on temporal, spatial, social, and hypothetical distance and found significant effects of high versus low-level construals in increasing and reducing the estimated psychological distance. Moreover, another study [38] asked people to explain a target person's action either by highlighting high-level construals (i.e., why did the person perform it?) or low-level construals (i.e., how did the person perform it?). The results showed that people who explained the action with the "why" (high-level construal) perceived greater social distance from the actor while the "how" (low-level construal) reduced the perceived social distance from the actor.

We argue that such findings have important implications for the conduct of a sustainability campaign as the distance is among the significant factors that decrease foreign firms willingness and ability to conduct CSR campaigns [19]. Despite significant implications for consumer psychology and foreign firms' sustainability campaign success, no study has applied the reverse CLT framework to develop practical communication strategies in the context of sustainability and corporate communications. Therefore, we propose that for corporates' sustainability communications, a high-level description of the activity (e.g., "save the planet") will generate more social distance from the host company while a low-level description of a sustainability campaign will reduce social distance.

Hypothesis 5 (H5). Consumer ethnocentrism will moderate the association between social distance perception and company evaluations through sustainability campaign evaluations (indirect effect); the negative effect of social distance will be stronger among the high consumer ethnocentrism group, compared to the low consumer ethnocentrism group.

Hypothesis 6 (H6). Consumer ethnocentrism will moderate the association between social distance perception and company evaluations (direct effect); the negative effect of social distance will be stronger among the high consumer ethnocentrism group, compared to the low consumer ethnocentrism group.

Hypothesis 7 (H7). A high-level construal (i.e., why, desirability) message will increase consumers' social distance perception from the host company of a sustainability campaign while a low-level construal (i.e., how, feasibility) message will reduce the social distance perception.

\section{Methods}

\subsection{Sampling and Participants}

An online survey experiment was conducted from 20 to 25 November 2018. We recruited 152 Chinese adult participants through an international online research agency (Macromill Embrain) that recruits volunteers from a panel made up of 550,029 Chinese adults. After receiving an online survey request, Macromill Embrain created an online survey webpage and sent it back to the authors to confirm the survey design. After the authors checked the survey design and procedure, a URL of the survey webpage was randomly sent to the panel members. The panel members who received the request voluntarily participated and received monetary incentives to complete the online survey requirement (in Chinese yuan, equivalent to 3 USD). Participants were randomly assigned to one of two messages and questionnaires, either the high-level construal $(n=76)$ or the low-level construal condition $(n=76)$. Participants consisted of 83 male $(54.6 \%)$ and 69 female (45.4\%) adults aged between 20 and 59 years: 20-29 $(n=41,27 \%), 30-39(n=36$, $23.7 \%), 40-49(n=42,27.6 \%)$, and 50-59 $(n=33,21.7 \%)(M=39.36, \mathrm{SD}=10.63)$. The most common living area was Beijing followed by Shanghai (23.9\%), Guangzhou (21.8\%), 
and others (20.5\%). After the requested number of responses was satisfied, the survey was closed, and the raw data were delivered to the authors.

\subsection{Design and Procedure}

First, we used a single-factor design and examined the effects of the two types of sustainability campaign messages (high vs. low construals) on social distance perception from the campaign host (H7). The measured social distance perception was then used as an independent variable to test the moderated mediation model from Figure 1 (H1-H6). At the beginning of the online survey experiment, subjects were briefed about the study purpose, procedure, voluntary nature of their participation, and were asked to sign a digital consent form to indicate that they understood and agreed with the procedure and purpose of this study. After completing demographic questions and the consumer ethnocentrism scale (CETSCALE), participants were randomly assigned to two groups (high vs. low construal level conditions) and were exposed to a sustainability campaign message highlighting either the goals of the campaign (high-level construal condition, $n=76$ ) or the means (low-level construal condition, $n=76$ ). After completing the questions relating to the construal level manipulation, participants rated social distance perception from the campaign host, campaign evaluations, and company evaluations.

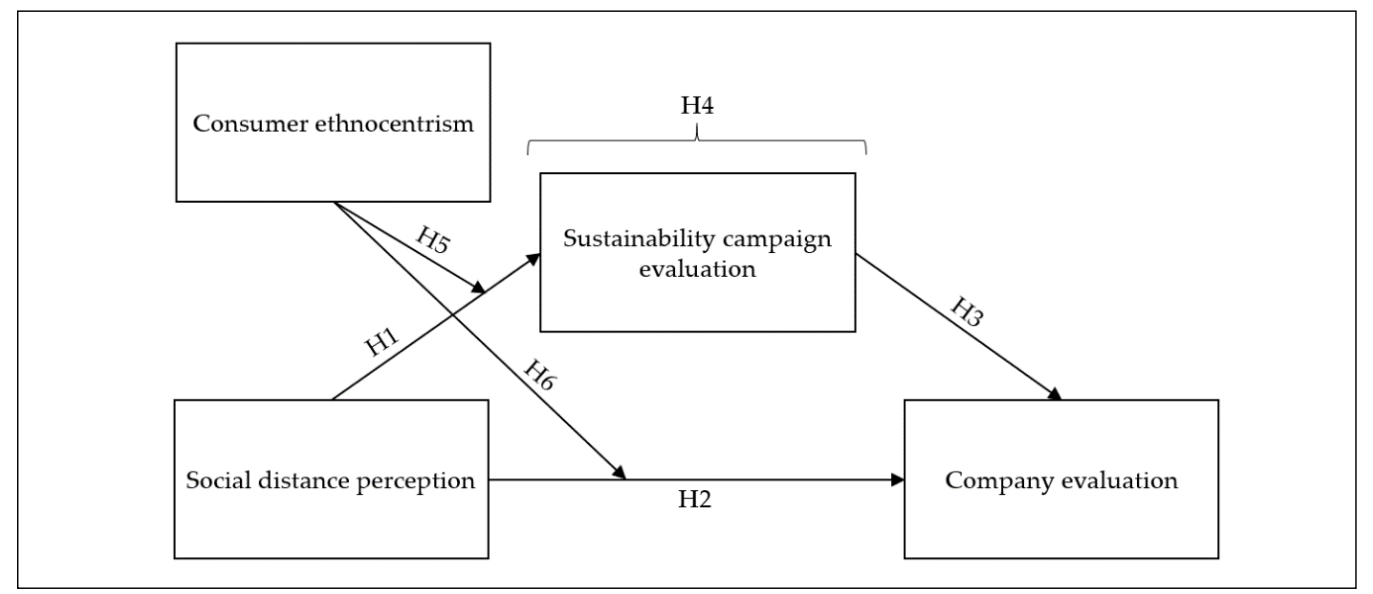

Figure 1. Proposed moderated mediation model.

\subsection{Message Design}

Adapting Lii, Wu, and Ding's [13] message design, two types of fictitious sustainability campaigns were created to prevent increasing confounding effects caused by previous experiences and attitudes toward the action (campaign) and the actor (company). The messages and the questionnaire were first created in English and translated into Chinese and cross-checked by two native Chinese speakers who are fluent in English. To be more specific, two translators, an English-Chinese bilingual professional translator and an English-Chinese bilingual communications-major doctoral student, independently translated the messages and the questionnaire. After the completion of the first drafts, they cross-checked each other's translations. The authors mediated between two translators until they agreed on the translation, and the authors and the two translators met in person for a meeting to confirm the final version of the Chinese translation.

At the beginning of the online survey, participants were asked to read either one of the two types of messages after being told that the message is a part of a company's sustainability campaign message. The company name was anonymized. The high-level construal message contained information about the reasons why the issue is important as well as the expected results of the campaign (ends). The low-level construal message, on the other hand, highlighted the details about the means to carry out the purpose (see Table 1). 
Table 1. High-level construal message vs. low-level construal message.

\begin{tabular}{ll}
\hline & "Save the Planet" \\
& Each year, 12.7 million metric tons of plastic waste are \\
dumped into the oceans, which is equal to a truck of & garbage dumped into the oceans every minute. In total, \\
& $14 \%$ of plastic waste is collected and only $2 \%$ is reused. \\
Experts say that at this rate, plastic waste will soon & outnumber the amount of fish in the ocean. Through this \\
& campaign, our company aims to save more than 1000 sea \\
turtles, save $¥ 820$ billion each year, and prevent seafood \\
toxins and air pollution from killing animals and humans. \\
"Plastic-Free Tuesday" \\
On plastic-free Tuesdays, our branches skip using plastic \\
bags, plates, straws, and any other disposable plastic \\
materials. We also give $¥ 5$ discount and a stuffed sea turtle \\
to customers who bring their tumblers and/or non-plastic \\
containers on Tuesdays. Moreover, another $¥ 5$ will be \\
donated to the “Save the Sea" campaign on every \\
plastic-free purchase. We are planning to extend this \\
plastic-free Tuesday to plastic-free weekends, and our \\
employees are already making it a habit inside and outside \\
of our restaurant.
\end{tabular}

\subsection{Manipulation Check}

To confirm whether the high-level and low-level messages were manipulated as intended, the participants were asked to select a number from 1 to 7 that best describes how they feel about two contradicting statements, e.g., (1) "the message communicates why the company is conducting the campaign" vs. "the message communicates how the company is conducting the campaign". A $t$-test showed that the mean of the two items showed a significant difference between the two manipulation groups $(t(150)=15.80, p<0.000)$.

\subsection{Operational Definitions}

\subsubsection{Social Distance Perception}

To best serve the study purpose, this study modified items from Edwards, Lee, and Ferle's [26] (p. 41) study to measure consumers' social distance perception from a sustainability campaign host, e.g., (1) "I think the company and I share similar values", (2) "I think people in the company hold the same worldview as me", (3) "I think I am similar to the people who work for the company". Moreover, participants were also asked if they felt that they are (4) emotionally close to the company and (5) the people who work for the company, and (6) share a similar philosophy with the CEO of the company. Six items were measured on a seven-point Likert-type scale, and its inter-item reliability, as measured using Cronbach's alpha, was $0.96(M=3.27, S D=1.24)$.

\subsubsection{Consumer Ethnocentrism}

This study employed and modified Shimp and Sharma's [29] (p. 282) CETSCALE to measure consumers' ethnocentric tendencies. Six items were modified for this study: (1) "Chinese people should always buy Chinese-made products instead of imports", (2) "purchasing foreign-made products is unpatriotic", (3) "we should purchase products manufactured in China instead of letting other countries get rich off us", (4) "Chinese should not buy foreign products, because this hurts Chinese businesses and causes unemployment", (5) "foreign products should be taxed heavily to reduce their entry into China", and (6) "we should buy from foreign countries only those products that we cannot obtain within our own country". Inter-item reliability, as measured using Cronbach's alpha, was $0.933(M=3.55, S D=1.32)$. 


\subsubsection{Company Evaluations}

This study employed and modified company evaluation scales from previous studies $[13,39,40]$ and asked participants to rate seven items on a seven-point Likert-type scale: (1) "I think Company A is acting responsibly", (2) "I am willing to support Company $\mathrm{A}^{\prime}$, (3) "Company A can benefit our society", (4) "I am willing to purchase Company A's products", (5) "I think I will purchase from Company A if the quality is better than its competitors'", (6) "I think I will give positive recommendations about Company A", and (7) "I think I will give positive recommendations about Company A's products" (Cronbach's alpha $=0.924, M=6.02, S D=0.80$ ).

\subsubsection{Sustainability Campaign Evaluations}

Sustainability campaign evaluations were measured with six items on a seven-point Likert-type scale: (1) "I think the campaign deals with an important social problem", (2) "I think the campaign is helpful to society", (3) "I think the campaign can help solve an important social problem", (4) "I am willing to support the campaign", (5) "I will tell my friends or family about this campaign", and (6) "I will tell people to support this campaign" (Cronbach's alpha $=0.906, M=6.02, S D=0.79$ ).

\section{Results}

\subsection{Hypothesis 1-Hypothesis 6}

The SPSS PROCESS macro [41] was employed to examine the proposed moderated mediation model (H1-H6) under 95\% confidence levels. First, the results showed that the effect of social distance perception on sustainability campaign evaluations was not statistically significant $(\beta(S E)=-0.09(0.05), p=0.09)(\mathrm{H} 1)$. However, the results showed that social distance perception significantly affected company evaluations $(\beta(S E)=-0.13(0.06)$, $p<0.05)$, which indicates that people with higher social distance perception from a company are more likely to show negative company evaluations, compared to people with lower social distance perception (H2). The results also showed that the positive effect of sustainability campaign evaluations on company evaluations was significant $(\beta(S E)=0.86(0.05)$, $p<0.001)(\mathrm{H} 3)$. The results did not support hypothesis 4 that sustainability campaign evaluations will mediate the effect of social distance perception on company evaluations (see Table 2).

Table 2. Results of mediation analysis (Model 4).

\begin{tabular}{|c|c|c|c|c|c|}
\hline Direct and Total Effects & $\beta$ & $S E$ & $t$ & $R^{2}$ & LLCI/ULCI \\
\hline Social distance perception $\rightarrow$ Sustainability campaign evaluations (H1) & -0.09 & 0.05 & -1.69 & 0.02 & $-0.19 / 0.01$ \\
\hline Social distance perception $\rightarrow$ Company evaluations (H2) & -0.13 * & 0.06 & -2.31 & 0.04 & $-0.24 /-0.02$ \\
\hline Sustainability campaign evaluations $\rightarrow$ Company evaluations (H3) & $0.86^{* * *}$ & 0.05 & 18.05 & & $0.77 / 0.95$ \\
\hline Bootstrapped indirect effect & \multicolumn{2}{|c|}{ Boot $S E$} & \multicolumn{2}{|c|}{ Boot LLCI } & Boot ULCI \\
\hline Bootstrap result for indirect effect $(\mathrm{H} 4)$ & \multicolumn{2}{|c|}{0.04} & \multicolumn{2}{|c|}{-0.17} & 0.00 \\
\hline
\end{tabular}

$\mathrm{N}=152 . \quad \mathrm{LLCI}=$ lower level confidence interval; ULCI $=$ upper level confidence interval. Bootstrap sample size $=5000 ;{ }^{*} p<0.05$, $* * * p<0.001$.

The results supported hypothesis 5 that the moderating role of consumer ethnocentrism on the conditional indirect effect of social distance perception on company evaluations through susceptibility campaign evaluations was significant $(\beta(S E)=-0.07(0.03), 95 \%$ biascorrected bootstrap $\mathrm{CI}=-0.1406,-0.0194$ ) among people with medium to high consumer ethnocentrism (see Table 3). The results also showed that consumer ethnocentrism significantly moderates the relationship between social distance perception and company evaluations. However, the conditional direct effect of social distance perception on company evaluations was found to be only significant among the neutral consumer ethnocentrism group $(\beta(S E)=-0.06(0.03), t=-2.23, p<0.05,95 \% \mathrm{CI}=-0.1085,-0.0165)$. Even though it was not statistically significant, we also found a similar tendency among high consumer 
ethnocentrism group $(\beta(S E)=-0.08(0.04), t=-1.85, p=0.07,95 \% \mathrm{CI}=-0.1666,0.0055)$ (see Table 3).

Table 3. Results of moderated mediation analysis (Model 8).

\begin{tabular}{|c|c|c|c|c|c|c|c|c|c|}
\hline \multirow{2}{*}{ Predictor } & \multicolumn{4}{|c|}{ Sustainability Campaign Evaluations } & \multicolumn{5}{|c|}{ Company Evaluations } \\
\hline & $\beta$ & $S E$ & LLCI & ULCI & & $\beta$ & $S E$ & LLCI & ULCI \\
\hline Social distance perception & -0.09 & 0.05 & -0.20 & 0.01 & & $-0.06^{*}$ & 0.03 & -0.11 & -0.01 \\
\hline Sustainability campaign evaluations & & & & & & $0.85^{* * *}$ & 0.05 & 0.76 & 0.94 \\
\hline $\begin{array}{c}\text { Social distance } X \\
\text { Consumer ethnocentrism }\end{array}$ & -0.08 * & 0.04 & -0.16 & -0.01 & & -0.02 & 0.02 & -0.06 & 0.03 \\
\hline \multirow[t]{3}{*}{$R^{2}$} & \multicolumn{4}{|c|}{0.05} & \multicolumn{5}{|c|}{0.78} \\
\hline & \multicolumn{5}{|c|}{ Conditional indirect effect } & & & & \\
\hline & \multicolumn{2}{|c|}{ Bootstrapped indirect effect } & \multicolumn{2}{|c|}{ Boot $S E$} & \multicolumn{3}{|c|}{ Boot LLCI } & \multicolumn{2}{|c|}{ Boot ULCI } \\
\hline Index of moderated mediation & \multicolumn{2}{|c|}{-0.07} & \multicolumn{2}{|c|}{0.03} & \multicolumn{3}{|c|}{-0.1406} & \multicolumn{2}{|c|}{-0.0194} \\
\hline$-1 S D$ & \multicolumn{2}{|c|}{0.01} & \multicolumn{2}{|c|}{0.05} & \multicolumn{3}{|c|}{-0.0848} & \multicolumn{2}{|c|}{0.1070} \\
\hline$M$ & \multicolumn{2}{|c|}{-0.08} & \multicolumn{2}{|c|}{0.05} & \multicolumn{3}{|c|}{-0.1766} & \multicolumn{2}{|c|}{-0.0036} \\
\hline \multirow[t]{3}{*}{$+1 S D$} & \multicolumn{2}{|c|}{-0.17} & \multicolumn{2}{|c|}{0.07} & \multicolumn{3}{|c|}{-0.3357} & \multicolumn{2}{|c|}{-0.0615} \\
\hline & \multicolumn{4}{|c|}{ Conditional direct effect } & & & & & \\
\hline & \multicolumn{2}{|c|}{ Effect } & \multicolumn{2}{|l|}{$S E$} & $t$ & \multicolumn{2}{|r|}{ LLCI } & \multicolumn{2}{|c|}{ ULCI } \\
\hline$-1 S D$ & \multicolumn{2}{|c|}{-0.03} & \multicolumn{2}{|l|}{0.04} & -0.96 & \multicolumn{2}{|r|}{-0.1056} & & 0367 \\
\hline$M$ & & & 0.03 & & -2.23 & & -0.1085 & & .0165 \\
\hline$+1 S D$ & & & 0.04 & & -1.85 & & -0.1666 & & 0055 \\
\hline
\end{tabular}

$\mathrm{N}=152 . \quad$ LLCI $=$ lower level confidence interval; ULCI $=$ upper level confidence interval. Bootstrap sample size $=5000 ;{ }^{*} p<0.05$, $* * * p<0.001$.

The results of the PROCESS macro provided a partial explanation of the proposed model. Based on the results found from this analysis, we further attempted to clarify the relationship between the variables using a two-way analysis of variance (ANOVA). Unlike previous research on social distance perception that experimentally manipulated social distance perception, e.g., [13], we measured social distance perception as an independent variable to improve the measurement and accuracy problems that have been of major concerns of social distance perception studies. However, to add to the understanding of the relationship trend among the variables, we created groups based on the median values of the level of social distance perception (3.08) and consumer ethnocentrism (3.67) to compare the effects of social distance perception under high versus low consumer ethnocentrism conditions. While acknowledging the criticism on dichotomizing continuous data to categorical data [42], we conducted this second part of the analysis as additional evidence for the proposed model based on the argument that while dichotomizing may cause loss of information, it can significantly decrease the risk of data contamination [43].

According to a two-way ANOVA analysis, social distance perception had a significant effect on sustainability campaign evaluations, supporting $\mathrm{H} 1(F(1,151)=6.05, p<0.01)$. Again, consumer ethnocentrism did not have a direct main effect, but it significantly moderated the relationship between social distance perception and sustainability campaign evaluations $(F(1,151)=3.88, p<0.05)$. Table 4 further clarifies that people showed more positive evaluations when the perceived social distance was close $(M=6.25)$, compared to when the perceived social distance was distant $(M=5.67)$ in the high consumer ethnocentrism group $\left(F(1,151)=7.52, p<0.01, \eta^{2}=0.113\right.$ ), (see Table 4 and Figure 2 ). According to Cohen's [44] Eta squared guidelines for small, medium, and large effects $(0.01,0.059$, and 0.138$)$, the perceived social distance was also considered to have a large effect $\left(\eta^{2}=0.113\right)$ on campaign evaluations. 
Table 4. Simple main effect analysis for the two-way interaction between social distance and consumer ethnocentrism (sustainability campaign evaluations).

\begin{tabular}{|c|c|c|c|c|c|c|c|c|}
\hline \multirow[b]{2}{*}{ Consumer Ethnocentrism } & \multirow[b]{2}{*}{ Social Distance } & \multirow[b]{2}{*}{$\mathbf{N}$} & \multirow[b]{2}{*}{$M$} & \multirow[b]{2}{*}{$S D$} & \multicolumn{4}{|c|}{ ANOVA } \\
\hline & & & & & SS & $d f$ & MS & $\begin{array}{c}F \\
\text { (sig.) }\end{array}$ \\
\hline \multirow{2}{*}{ High } & Close & 31 & 6.25 & 0.55 & \multirow{2}{*}{5.04} & \multirow{2}{*}{1} & \multirow{2}{*}{5.04} & \multirow{2}{*}{$7.52 * *$} \\
\hline & Distant & 30 & 5.67 & 1.03 & & & & \\
\hline \multirow{2}{*}{ Low } & Close & 45 & 6.10 & 0.63 & \multirow{2}{*}{0.09} & \multirow{2}{*}{1} & \multirow{2}{*}{0.09} & \multirow{2}{*}{0.15} \\
\hline & Distant & 46 & 6.03 & 0.87 & & & & \\
\hline
\end{tabular}

Dependent variable $=$ sustainability campaign evaluations, ${ }^{* *} p<0.01$.

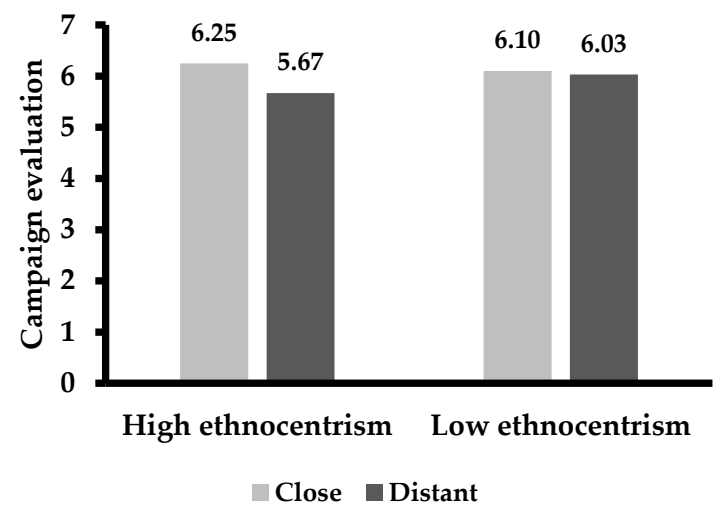

Figure 2. Effects of social distance on campaign evaluations moderated by consumer ethnocentrism.

Consistent with the findings from the PROCESS MACRO analysis, the results from a two-way ANOVA found a significant effect of social distance perception on company evaluations, supporting $\mathrm{H} 2(F(1,151)=12.15, p<0.001)$. Even though consumer ethnocentrism did not have a direct main effect, it significantly moderated the relationship between social distance perception and company evaluations, also supporting H6 $(F(1,151)=7.27$, $p<0.01)$. A simple main effect analysis further clarified that the participants showed more positive evaluations when the perceived social distance was close $(M=6.30)$, compared to when the perceived social distance was distant $(M=5.52)$. The effect was statistically significant only for the high consumer ethnocentrism group $(F(1,151)=15.96, p<0.001$, $\eta^{2}=0.183$ ), (see Table 5 and Figure 3). According to Cohen's [44] Eta squared guidelines for small, medium, and large effects $(0.01,0.059$, and 0.138$)$, the perceived social distance was considered to have a large effect $\left(\eta^{2}=0.183\right)$ on company evaluations.

Table 5. Simple main effect analysis for the two-way interaction between social distance and consumer ethnocentrism (company evaluations).

\begin{tabular}{|c|c|c|c|c|c|c|c|c|}
\hline \multirow[b]{2}{*}{ Consumer Ethnocentrism } & \multirow[b]{2}{*}{ Social Distance } & \multirow[b]{2}{*}{$\mathbf{N}$} & \multirow[b]{2}{*}{$M$} & \multirow[b]{2}{*}{$S D$} & \multicolumn{4}{|c|}{ ANOVA } \\
\hline & & & & & SS & $d f$ & MS & $\begin{array}{c}F \\
\text { (sig.) }\end{array}$ \\
\hline \multirow{2}{*}{ High } & Close & 31 & 6.30 & 0.55 & \multirow{2}{*}{9.17} & \multirow{2}{*}{1} & \multirow{2}{*}{9.17} & \multirow{2}{*}{$15.96^{* * *}$} \\
\hline & Distant & 30 & 5.52 & 1.05 & & & & \\
\hline \multirow{2}{*}{ Low } & Close & 45 & 6.13 & 0.59 & \multirow{2}{*}{0.22} & \multirow{2}{*}{1} & \multirow{2}{*}{0.22} & \multirow{2}{*}{0.39} \\
\hline & Distant & 46 & 6.03 & 0.80 & & & & \\
\hline
\end{tabular}

Dependent variable $=$ company evaluations, ${ }^{* * *} p<0.001$. 


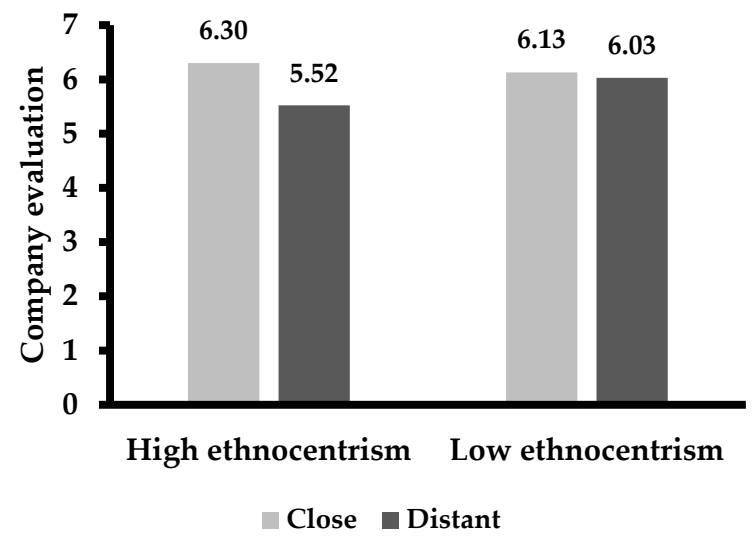

Figure 3. Effects of social distance on company evaluations moderated by consumer ethnocentrism.

\subsection{Hypothesis 7}

Finally, H7 examined whether the high-level construal message (why, desirability) generates a higher degree of social distance, compared to the low-level construal message (how, feasibility). A $t$-test revealed that there was a significant difference between the level of perceived social distance depending on the level of construals in the sustainability campaign message $(t(150)=19.02, p<0.001)$. As expected, the participants perceived higher social distance from the campaign host when they were exposed to the high-level construal message $(M=4.31, S D=0.79)$, compared to when they were exposed to the low-level construal message $(M=2.24, S D=0.53)$ (see Figure 4$)$.

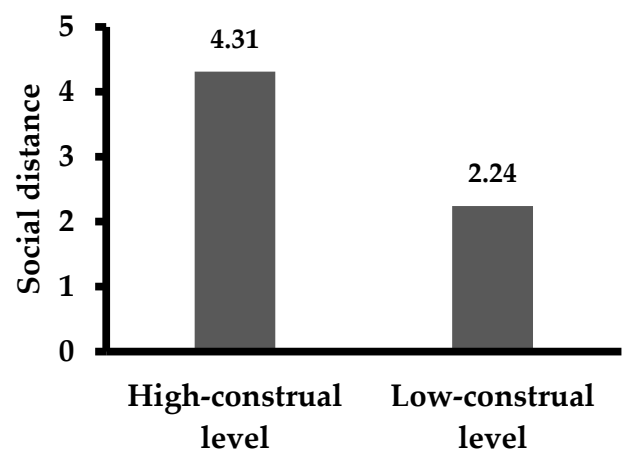

Figure 4. Effect of construal level framing on social distance.

\section{Discussion and Conclusions}

This study clarified the effect of social distance perception on sustainability campaign evaluations, (H1) and company evaluations (H2). It further tested the effect of sustainability campaign evaluations on company evaluations (H3) and how it mediates the relationship between social distance perception and company evaluations (H4). Moreover, we also examined how consumer ethnocentrism moderates the indirect (H5) and direct effect (H6) of social distance perception on company evaluations. Finally, this study also tested the reverse effect of construal level framing on social distance perception (H7).

The SPSS PROCESS macro found a significant effect of social distance perception on company evaluations (H2) but not on sustainability campaign evaluations (H1). Even though we found a significant association between social distance perception and sustainability campaign evaluations by dichotomizing social distance perception, we argue that such results imply that social distance perception has a stronger relationship with actor involved variables such as company evaluations. Moreover, hypothesis 3 found a significant relationship between campaign evaluations and company evaluations. In line with previous studies [13,20-24], this study adds to the findings that social distance perception from a company may hinder fair consumer evaluations and that social distance 
mitigation can help foreign firms overcome negative consumer evaluations and the costs of LOF.

On the other hand, the results found no significant mediating role of sustainability campaign evaluations between social distance perception and company evaluations (H4). However, the SPSS PROCESS macro model 8 found a significant indirect effect of social distance perception on company evaluations through sustainability campaign evaluations among people with medium to high consumer ethnocentrism levels (H5). This result implies that people with medium to high consumer ethnocentrism levels are more likely to change their evaluations for a company based on their evaluations for the company's sustainability campaign initiatives. Hypothesis 5 provided evidence that consumer ethnocentrism is indeed an important threat to foreign firms and that reducing consumers' social distance perceptions can be more important for foreign firms in a market with higher consumer ethnocentrism. The results imply the need for a consumer ethnocentrism analysis of foreign markets and that it should be conducted per specific segment, because there may be a significant difference in the level of consumer ethnocentrism within a country. If a foreign company's target segment is in a high consumer ethnocentrism group, we suggest that the company should prioritize reducing the social distance perceptions, whereas if the target segment is in a low consumer ethnocentrism group, companies may have more freedom to focus on other segment-specific strategies.

It was also partially supported that consumer ethnocentrism moderates the direct effect of social distance perception on company evaluations (H6) among neutral the consumer ethnocentrism group. We further tested this hypothesis using a two-way AVOVA analysis by dichotomizing social distance perception and consumer ethnocentrism using the median values. The second analysis showed a significant moderating effect of consumer ethnocentrism that people with high consumer ethnocentrism are affected more by social distance perception when evaluating a company. Even though such results showed general tendencies of the proposed relationship, dichotomizing may have caused some limitations in the second analysis. Despite the argument that dichotomization may decrease the risk of contamination of the data [43], we suggest that future studies should test the hypothesis with a larger sample size and by experimentally manipulating social distance perception.

Finally, this study examined the effect of construal level framing (high vs. low) on social distance perceptions and found significant evidence that high-level construal campaign messages incur more social distance than low-level construal messages (H7). It is expected that this result will be useful to foreign firms suffering from foreignness or unfair evaluations due to a lack of a sense of belonging. For example, communicating specifically how firms are delivering company goals or sustainability campaign purposes, which are low-level concerns, may help foreign firms by creating a sense of social closeness. The findings from the moderating effects of consumer ethnocentrism support the argument that social distance perception is an important obstacle to foreign firms and highlight the need for communication efforts to reduce social distance. We argue that the result from $\mathrm{H} 7$ adds an important implication to the discussion on LOF and foreign corporate communications as it provides a direction for the message strategies for the mitigation of social distance perceptions.

The findings also add to the CLT literature by providing additional support for the reverse direction of the theory. The traditional CLT focuses on the effect of psychological distance perceptions on the use of construal levels or the interaction effects between the two variables. There have been attempts to reveal the reverse direction [38,45-47], but no study has employed this notion to test its applicability in practical business settings. Moreover, this study improved the practical implications of CLT by applying the theory to a realm of corporate communications. To be more specific, this study provided evidence on the possibility of social distance manipulation through sustainability campaigns and thus has made a valid theoretical contribution to the theory.

Another contribution of this study is that it has added to the LOF and sustainability literature by emphasizing consumer-centered social aspects. Even though there have been 
attempts to study discrimination for foreign companies, they have been focused on reducing the physical costs of foreignness such as transportation, employment, and language. Moreover, to the best of our knowledge, the majority of the CSR and sustainable business studies have highlighted economic returns and paid less attention to consumer-focused psychological variables [19]. Our results suggest that more consumer-oriented studies should be conducted to provide suggestions for practical communication strategies to overcome LOF. Such an approach will be particularly useful as foreign firms suffer from the irrational rejection caused by an intangible psychological distance from local consumers. This study adds to the efforts to clarify the influence of the emotional or personal social distance, which is less explored, unlike the tangible distance that prevails in the international business literature.

This study has put efforts into defining the social distance concept to best represent social distance that local consumers feel from foreign firms within the theoretical framework of CLT. It is more difficult to define and measure social distance, compared to other distance dimensions such as temporal or geographical distance, because it is intangible and may vary depending on different perspectives and contexts. For example, in the international business literature, social distance has been synonymized with language or cultural differences, whereas in human communications, it was described as in-group/out-group perception, familiarity, and similarity $[19,33,34,38,48]$. This study separated the definition of social distance perception from the social distance caused by tangible differences or communication difficulties caused by geography, language, and culture and highlighted the irrational anti-foreign sentiment that is effective beyond general localization efforts. This study also excluded familiarity perceptions as an indicator of social distance, because familiarity can be both a condition of favorability and cause likes or dislikes of a target, which makes it less relevant to this study where the company names were anonymized. Therefore, this study focused on the similarity perceptions of beliefs, values, and emotional closeness that are more relevant to the context of sustainability communications. This view was also taken by other researchers in both the international management and the CLT literature $[13,19,26,28]$, proving the validity of the measure in representing the research purpose and theoretical framework of this study.

Despite the implications, this study has limitations. First, this study only investigated Chinese participants who live in major cities in China such as Beijing, Shanghai, and Guangzhou. Such regional limitations and limited sample size may weaken the generalizability of this study. We performed bootstrapping to generate 5000 samples to prevent a possible biased error estimate and to improve statistical significance; however, we propose that increasing the sample size and comparing the effects in different cultures will be important future directions. A cross-cultural comparison will broaden the generalizability of this study, which is limited to the context of the Chinese market. Moreover, some limitations require further discussion in terms of the anonymity and unidimensionality of the message design. The company names were not exposed to the participants in the message design. We rationalized this decision based on the fact that this study attempted to exclude prior attitudes toward a specific company or country and to ensure the sole influence of construal level framing on social distance perceptions. However, this approach may also have reduced the practicality of the results.

Another possible future direction to improve practicality is to include different dimensions of the psychological distance. This study focused only on the perception of social distance; however, in reality, there are multiple dimensions, such as spatial, temporal, and cultural distance perceptions. Investigating the effects of both physical and social distance perceptions on LOF will add theoretical and practical values to the current findings. Additionally, the choice of a plastic reduction campaign was rationalized by noting that China is among the biggest victims of environmental impacts. However, the topic itself may have contained distance perceptions of time and space. Future studies may compare the effects of construal level framing on campaign topics with different levels of psychological distance. 
Author Contributions: Conceptualization, G.P. and H.S.P.; Data curation, G.P.; Formal analysis, G.P.; Funding acquisition, G.P.; Investigation, G.P.; Methodology, G.P. and H.S.P.; Project administration, G.P.; Supervision, H.S.P.; Writing—original draft, G.P.; Writing—review \& editing, G.P. and H.S.P. All authors have read and agreed to the published version of the manuscript.

Funding: This research was funded by The Beautiful Foundation in South Korea.

Acknowledgments: This paper is part of a doctoral dissertation (title: Psychological Distance Matters in CSR Communication: The Case of Foreign Firms in China) submitted by the first author to the Department of Media and Communication, Sungkyunkwan University, South Korea.

Conflicts of Interest: The authors declare no conflict of interest. The funders had no role in the design of the study; in the collection, analyses, or interpretation of data; in the writing of the manuscript, or in the decision to publish the results.

\section{References}

1. Quartz. Available online: https:/ /qz.com/923761/a-history-of-china-retaliating-against-foreign-companies-carrefour-toyotahonda-kfc-lotte/ (accessed on 1 October 2020).

2. Froese, F.J.; Sutherland, D.; Lee, J.Y.; Liu, Y.; Pan, Y. Challenges for foreign companies in China: Implications for research and practice. Asian Bus. Manag. 2019, 18, 249-262. [CrossRef]

3. Chinese Daily. Available online: https://www.chinadaily.com.cn/business/2016-05/17/content_25324074.htm (accessed on 27 November 2020).

4. Kolk, A.; Hong, P.; van Dolen, W. Corporate social responsibility in China: An analysis of domestic and foreign retailers' sustainability dimensions. Bus. Strat. Environ. 2010, 19, 289-303. [CrossRef]

5. Tokas, K.; Yadav, K. Foreign ownership and corporate social responsibility: The case of an emerging market. Glob. Bus. Rev. 2020. [CrossRef]

6. Liberman, N.; Trope, Y.; Wakslak, C. Construal level theory and consumer behavior. J. Consum. Psycho. 2007, 17, 113-117. [CrossRef]

7. Byrne, D. Attitudes and attraction. J. Exp. Soc. Psychol. 1969, 4, 35-89.

8. Burt, R.S. Social contagion and innovation: Cohesion versus structural equivalence. Am. J. Sociol. 1987, 92, 1287-1335. [CrossRef]

9. Metzger, M.J.; Flanagin, A.J. Credibility and trust of information in online environments: The use of cognitive heuristics. J. Pragmat. 2013, 59, 210-220. [CrossRef]

10. Gómez, Á.; Dovidio, J.F.; Huici, C.; Gaertner, S.L.; Cuadrado, I. The other side of we: When outgroup members express common identity. Pers. Soc. Psychol. Bull. 2008, 34, 1613-1626. [CrossRef]

11. Bourgeois, M.; Friedkin, N.E. The distant core: Social solidarity, social distance and interpersonal ties in core-periphery structures. Soc. Netw. 2001, 23, 245-260. [CrossRef]

12. Buchan, N.R.; Johnson, E.J.; Croson, R.T. Let's get personal: An international examination of the influence of communication, culture and social distance on other regarding preferences. J. Econ. Behav. Organ. 2006, 60, 373-398. [CrossRef]

13. Lii, Y.S.; Wu, K.W.; Ding, M.C. Doing good does good? Sustainable marketing of CSR and consumer evaluations. Corp. Soc. Responsib. 2013, 20, 15-28. [CrossRef]

14. Tumasjan, A.; Strobel, M.; Welpe, I. Ethical leadership evaluations after moral transgression: Social distance makes the difference. J. Bus. Ethics 2011, 99, 609-622. [CrossRef]

15. Coenen, J.; Bager, S.; Meyfroidt, P.; Newig, J.; Challies, E. Environmental governance of China's belt and road initiative. Environ. Policy. Gov. 2020, 2020, 1-15. [CrossRef]

16. Campbell, J.T.; Eden, L.; Miller, S.R. Multinationals and corporate social responsibility in host countries: Does distance matter? J. Int. Bus. Stud. 2012, 43, 84-106. [CrossRef]

17. Crilly, D.; Ni, N.; Jiang, Y. Do-no-harm versus do-good social responsibility: Attributional thinking and the liability of foreignness. Strateg. Manag. J. 2016, 37, 1316-1329. [CrossRef]

18. Maruyama, M.; Wu, L. Overcoming the liability of foreignness in international retailing: A consumer perspective. J. Int. Manag. 2015, 21, 200-210. [CrossRef]

19. Eden, L.; Miller, S.R. Distance matters: Liability of foreignness, institutional distance and ownership strategy. Adv. Int. Manag. 2003, 16, 187-221.

20. Yoon, Y.; Gürhan-Canli, Z.; Schwarz, N. The effect of corporate social responsibility (CSR) activities on companies with bad reputations. J. Consum. Psychol. 2006, 16, 377-390. [CrossRef]

21. Teng, W. Importance of corporate image for domestic brands moderated by consumer ethnocentrism. J. Prod. Brand. Manag. 2019, 29, 257-272. [CrossRef]

22. Widyastuti, S.; Said, M.; Siswono, S.; Firmansyah, D.A. Customer trust through green corporate image, green marketing strategy, and social responsibility: A case study. Eur. Res. Stud. 2019, 22, 83-99. [CrossRef]

23. Choi, C.S.; Cho, Y.N.; Ko, E.; Kim, S.J.; Kim, K.H.; Sarkees, M.E. Corporate sustainability efforts and e-WOM intentions in social platforms. Int. J. Advert. 2019, 38, 1224-1239. [CrossRef] 
24. Chernev, A.; Blair, S. When sustainability is not a liability: The halo effect of marketplace morality. J. Consum. Psychol. 2020, 1-19. [CrossRef]

25. Marin, L.; Ruiz, S.; Rubio, A. The role of identity salience in the effects of corporate social responsibility on consumer behavior. J. Bus. Ethics 2009, 84, 65-78. [CrossRef]

26. Edwards, S.M.; Lee, J.K.; Ferle, C.L. Does place matter when shopping online? Perceptions of similarity and familiarity as indicators of psychological distance. J. Interact. Mark. 2009, 10, 35-50. [CrossRef]

27. Leonidou, L.C.; Barnes, B.R.; Talias, M.A. Exporter-importer relationship quality: The inhibiting role of uncertainty, distance, and conflict. Ind. Mark. Manag. 2006, 35, 576-588. [CrossRef]

28. Tajfel, H. Social psychology of intergroup relations. Annu. Rev. Psychol. 1982, 33, 1-39. [CrossRef]

29. Shimp, T.A.; Sharma, S. Consumer ethnocentrism: Construction and validation of the CETSCALE. J. Mark. Res. 1987, 24, 280-289. [CrossRef]

30. Ding, Q.S. Chinese products for Chinese people? Consumer ethnocentrism in China. Int. J. Retail. Distrib. 2017, 45, 550-564. [CrossRef]

31. Ramsaran-Fowdar, R.R. Are males and elderly people more consumer ethnocentric. World J. Manag. 2010,2 , 117-129.

32. Supphellen, M.; Grønhaug, K. Building foreign brand personalities in Russia: The moderating effect of consumer ethnocentrism. Int. J. Advert. 2003, 22, 203-226. [CrossRef]

33. Trope, Y.; Liberman, N. Construal-level theory of psychological distance. Psychol. Rev. 2010, 117, 440-463. [CrossRef]

34. Liviatan, I.; Trope, Y.; Liberman, N. Interpersonal similarity as a social distance dimension: Implications for perception of others' actions. J. Exp. Soc. Psychol. 2008, 44, 1256-1269. [CrossRef]

35. Fujita, K.; Henderson, M.D.; Eng, J.; Trope, Y.; Liberman, N. Spatial distance and mental construal of social events. Psychol. Sci. 2006, 17, 278-282. [CrossRef]

36. Liberman, N.; Trope, Y. The role of feasibility and desirability considerations in near and distant future decisions: A test of temporal construal theory. Pers. Soc. Psychol. 1998, 75, 5-18. [CrossRef]

37. Liberman, N.; Förster, J. Distancing from experienced self: How global-versus-local perception affects estimation of psychological distance. J. Pers. Soc. Psychol. 2009, 97, 203-216. [CrossRef]

38. Stephan, E.; Liberman, N.; Trope, Y. The effects of time perspective and level of construal on social distance. J. Exp. Soc. Psychol. 2011, 47, 397-402. [CrossRef]

39. Moosmayer, D.C.; Fuljahn, A. Consumer perceptions of cause related marketing campaigns. J. Consum. Mark. 2010, 27, 543-549. [CrossRef]

40. Putrevu, S.; Lord, K.R. Comparative and noncomparative advertising: Attitudinal effects under cognitive and affective involvement conditions. J. Advert. 1994, 23, 77-91. [CrossRef]

41. Hayes, A.F. Partial, conditional, and moderated moderated mediation: Quantification, inference, and interpretation. Commun. Monogr. 2018, 85, 4-40. [CrossRef]

42. Fitzsimons, G.J. Death to dichotomizing. J. Consum. Res. 2008, 35, 5-8. [CrossRef]

43. Shentu, Y.; Xie, M. A note on dichotomization of continuous response variable in the presence of contamination and model misspecification. Stat. Med. 2010, 29, 2200-2214. [CrossRef] [PubMed]

44. Cohen, J. Statistical Power Analysis for the Behavioral Sciences; Erlbaum: Hillsdale, NJ, USA, 1988.

45. McCrea, S.M.; Liberman, N.; Trope, Y.; Sherman, S.J. Construal level and procrastination. Psychol. Sci. 2008, 19, 1308-1314. [CrossRef]

46. Wakslak, C.; Trope, Y. The effect of construal level on subjective probability estimates. Psychol. Sci. 2009, 20, 52-58. [CrossRef] [PubMed]

47. Libby, L.K.; Shaeffer, E.M.; Eibach, R.P. Seeing meaning in action: A bidirectional link between visual perspective and action identification level. J. Exp. Psychol. Gen. 2009, 138, 503-516. [CrossRef] [PubMed]

48. Zhao, M.; Xie, J. Effects of social and temporal distance on consumers' responses to peer recommendations. J. Mark. Res. 2011, 48, 486-496. [CrossRef] 